\title{
Adoption of Mobile Commerce and Service in Adentan Municipality of Ghana: An Examination of Factors Influencing Small Scale Enterprises
}

\author{
Joseph Kwadwo Tuffour ${ }^{1}$, Dinah Akuffo ${ }^{2}$, Awuah Ayebi Kofi' ${ }^{2}$, Philip Agyemang Frimpong ${ }^{2}$, Terrick Sasu $^{2}$ \\ ${ }^{1}$ Research and Consultancy Centre, University of Professional Studies, Accra, Ghana \\ ${ }^{2}$ Department of Banking and Finance, University of Professional Studies, Accra, Ghana \\ Correspondence: Joseph Kwadwo Tuffour, Research and Consultancy Centre, University of Professional Studies, \\ Accra, Ghana.
}

Received: September 5, 2018

Accepted: October 4, 2018

Online Published: October 16, 2018

doi:10.5539/ibr.v11n11p109

URL: https://doi.org/10.5539/ibr.v11n11p109

\begin{abstract}
After the introduction of mobile commerce and services, people have accepted, adopted and used the services for various purposes. However, little attention has been given to its continual usage in small scale enterprise sector in Ghana. Also, studies on the benefits to businesses and barriers of use of mobile commerce and service have been carried out, but the extension of the studies to include examination of the effect of social and demographic factors of small business owners on mobile services use is lacking in the small scale enterprise sector in Ghana. This study investigates the factors which determine the adoption of mobile commerce and services among small scale enterprises in the Adentan Municipality of Ghana. The objective of the study is to determine the effects of demographic factors, experience and attitude on the adoption of mobile commerce and service. Data was collected using questionnaires administered to 400 owners of small scale enterprises in Adentan Municipality. Using structural equation model analysis, the results show that males have less attitude to use mobile commerce and service than females. Also, as people age, attitude to use mobile commerce and service improves. Education and experience have positive effect on attitude to use mobile commerce and service. On the contrary, there is a negative effect of income on attitude. There is a significant positive effect of attitude on mobile commerce and service's actual usage. The study recommends that, internet service practitioners should develop effective strategies and tactics to improve the attitude to use mobile commerce and service among small businesses owners in Ghana.
\end{abstract}

Keywords: demographic factors, small enterprises, attitude, mobile commerce and services, Adentan Municipality

\section{Background of the Study}

Around the world, mobile commerce and service are being adopted as the latest trend to undertake business transactions. Mobile commerce and service is widening the approach through which business undertake transaction, from a simple traditional approach to a larger and multifaceted system of intra and inter-firm cooperation. Mobile commerce and service comprise the delivery of products and services from one entity to the other. This transmission is done via wireless technologies. The purpose is to enable the use of internet business activities without necessarily facing any restrictions of either time or space. Studies (Allil \& Khan, 2016; Kim, Mirusmonov \& Lee, 2010; Mallat, Rossi, Tuunainen \& Oorni, 2009) have shown that mobile commerce and service have important effects on business and society. Mobile commerce and service have experienced a substantial growth since they were introduced. A number of reasons have been provided. These include rapid proliferation and improvement of mobile devices as well as the advantages brought by anytime-anywhere connectivity and use. This notwithstanding, certain factors have hindered consumers' usage of mobile commerce and service. These factors include cost of access and low access securities. One key factor is that, managerial support and enabling regulatory environment have important roles to play in stimulating SMEs use of mobile commerce and service.

According to Lee and Lee (2007), mobile commerce is conceptualized to all forms of business transactions using mobile or wireless networks. Ngai and Gunasekaran (2007) referred to mobile commerce as the conduct of 
commerce via wireless devices. Mobile services are activities that offer benefits to businesses and individuals of the use of mobile technology, particularly mobile communication and financial transactions. In the case of Ghana, the activities of mobile money is gaining roots. The Bank of Ghana reports that a growth rate of $129.5 \%$ in mobile money transactions from 2015 to 2016 (Bank of Ghana, 2017) as the economy experiences growth (Tuffour \& Owusu, 2018; Tuffour \& Mensah, 2018).

According to Kim, Mirusmonov and Lee (2010), with recent advances in mobile technologies, mobile commerce is having an increasingly profound impact on our daily lives. This is beginning to offer interesting and advantageous new services to both businesses and customers. Kim et al. (2010) analysed the impact of mobile payment system features and user-centric factors on mobile payment usage across different types of mobile payment users. The conclusion from these authors suggested new directions for future research in the emerging field (Kim, Mirusmonov \& Lee, 2010). Their research focused more on the recent advances in mobile technologies but touched a little bit on the challenges facing them. In light of the challenges which inhibit mobile commerce and service operations, Zhou (2011) reported that little attention has been given to analysis of continual use of mobile service.

Mallat, Rossi, Tuunainen and Oorni (2009) studies suggested the need to extend mobile services use study to other related areas. Bouwman, Carlsson, Molina-Castillo and Walden (2007) analysed the importance of understanding the role of barriers and benefits of mobile services. It was indicated that understanding actual use of mobile facilities depends on the characteristics of the services involved. However, the study did not include analysis of the effects of user socio-demographic variables on mobile commerce and service. This is covered in the present study.

According to Dholakia and Kshetri (2004), adoption and usage of mobile commerce and service have been highly variable among countries. This is because the adoption of mobile service and technology has not followed one single acceptable trend. The differences in adoption and usage identified across different people contexts is attributable to differences that exists in a) mobile telecommunications infrastructure available, b) the range of mobile commerce and services, c) the marketing strategies utilised by mobile service providers, and d) underlying culture of the consumers of mobile services. This raises the need for country and sector specific studies, the small enterprises sector of Ghana being not an exception.

As a result of mobile adoption and usage behaviour, lack of comprehensive study between actual use and impact of socio-demographic contributors on mobile services and culture of the consumers of mobile are some contributing problems facing adoption of mobile commerce and service among SMEs in Ghana. Thus, this research examines the factors influencing small enterprises' adoption of mobile commerce and service, and challenges which inhibits their adoption in the Adentan Municipality. Specifically, to examine the effect of demographic factors, experience, income and attitude on actual usage of mobile commerce and service. The next section contains the literature review. Section three contains the methodology while section four contains the results and discussion. The last section contains the conclusion and policy implications of the study.

\section{Literature Review}

\subsection{Theoretical Literature Review}

According to Grandon and Pearson (2004), mobile commerce has been conceptualized in several ways. These different ways depend on the context and research objective for any study. Poon and Swatman (1999) indicates that, mobile commerce and services in SMEs is generally contextualised as the utilisation of ICT and applications to support business activities. Laudon and Traver (2003) refer to mobile commerce and service as technology that is deployed to support internet business transactions. The transactions can be between the mobile service utilizing organizations and their direct end customers on one hand and others within their business networks on the other. Meanwhile, Turban, King, Lee, Liang and Turban (2010) provided a more specific definition where they stated that "mobile commerce and service is the process of buying, selling, transferring, exchanging products, services and/or information using computer networks mostly the internet and intranets". In this research, the dependent variable of mobile commerce and service adoption is adapted from the definition of Turban et al. (2010) where mobile commerce embraces the exchanges of transaction information from the business to customers and suppliers through online networks.

Different theories have been propounded by previous studies to examine and determine mobile commerce and service adoption and use. Some of these theories include the Theory of Reasoned Action, Diffusion of Innovation Theory, Technology Acceptance Model and the Theory of Planned Behavior among others. The Theory of Reasoned Action which was developed by Fishbein and Ajzen (1975) to predict the behavioural intention, indicated that a person's performance of a specified action is determined by his or her behavioural intention 
which equals the person's attitude combined with the subjective norm that represent the person's perception about service/ product importance (Alexander, 2006; Hennessy, 2012). The theory explains the relationship between attitude and behaviours of humans. The theory of Reasoned Action helps to understand an individual's basic motivation. The intention is known as behavioural intention. It is based on the belief that putting up a certain behaviour will lead to a specific outcome. Behavioural intention is important because the intentions "are determined by attitudes to behaviours and subjective norms". The theory suggests that when the intentions are stronger, then an increased effort to perform the behaviour, which also increases the likelihood for the behaviour to be performed. However, as there are differences between attitudes and subjective norms of individuals, they are unlikely to be given equal weights. Thus, based on the individual and the particular situation, different impacts on behavioural intention may result. Ajzen (1991) acknowledged the fact that, some actions are more likely to present problems of controls than others. Within this, there is limited certainty about that person carrying out the intentions.

Rogers' (1995) Diffusion of Innovations Theory is widely used by technology adoption frameworks which tries to explain factors affecting spreading of new ideas or technologies through cultures (Sahin, 2006). The theory indicated that there are four elements that affect ideas or technology diffusion: innovation, communication channels, time, and a social system (Rogers, 1995). The end result of this diffusion is that people adopt a new technology, idea, behaviour or product.

The Technology Acceptance Model (TAM) developed by Davis, Bagozzi and Warshaw (1989) explain user acceptance and usage of information systems, which states that the actual use of any new system is influenced by its perceived ease-of-use and perceived usefulness. Based on the theory of Reasoned Action, Davis et al. (1989) view is the acceptability of an information system. The TAM postulates that the use of a new system such as technology is determined by the behavioural intention, but on the other hand, the behavioural intention is determined by that person's attitude towards the use of the new system and also by his/her perception of its utility. In the view of Davis et al. (1989), the attitude of an individual determines the use of a new system, but up to a certain limit. The actual use also depends on the effect such use bring on performance. Therefore, even if a person is unwilling to welcome a new technological system, the probability that overtime such a person will use it is high when it is perceived that the system will improve performance. On the other hand, if there are two systems which have the same features, a user will find it more useful because he/she can choose what he finds easier to use (Dillion \& Morris, 1996).

The Theory of Planned Behavior (TPB) developed by Ajzen (1991) which is an extension of the Theory of Reasoned Action, states that the attitude toward behaviour, subjective norms (beliefs about significance of use) and perceived behavioural control directly influence behavioural intentions and behaviours. The TPB helps to understand how we can change the behaviour of people. The TBP is a theory which predicts deliberate behaviour, because behaviour can be deliberative and planned. These theories have been applied in various empirical studies, with varying results.

\subsection{Empirical Literature Review}

Past studies have demonstrated that relative advantage perceived from mobile service use is a significant determinant of technological adoption (Al-Qirim, 2007; Kaynak, Tatoglu \& Kula, 2005). Such past studies have advocated that the use of mobile commerce positively influences an organisation's performance, specifically in terms of growth (Qureshi, Keen \& Kamal, 2010; Raymond, Bergeron \& Blili, 2005), financial gain (Johnston, Wade \& McClean, 2007) and competitive advantage (Teo \& Ranganathan, 2004). However the study was more interested in how the SMEs perceived those benefits.

According to Grandon and Pearson (2004), the compatibility among mobile services, firm's cultural values and work practices is an important factor in determining mobile commerce adoption. Prior studies on mobile commerce adoption within SMEs found that mobile commerce/service adoption and usage is significantly affected by mobile commerce compatibility (Hong \& Zhu, 2006; Saffu, Walker \& Hinson, 2008).

Literature has found significant relationship between complexity of innovation and mobile commerce and service adoption (Huy \& Filiatrault, 2006; Jeon, Han \& Lee, 2006). Some SMEs perceived mobile commerce and service as complex to their businesses. Such SMEs are considered to possess low level of managerial and technical skills. Therefore, they perceived the implementation of mobile commerce and service as very challenging (Hussin, King \& Cragg, 2002).

It is known that, knowledge about mobile commerce and service is most influential at the early stage of adoption. However, it becomes less important when mobile commerce and service moves toward the higher end of adoption ladder (Roberts \& Toleman, 2007). In the Adentan Municipality, among the major barriers to mobile 
commerce and service adoption were: not having mobile commerce and service knowledge, lack of mobile commerce skills and lack of skilled workers to operate mobile commerce (Sulaiman \& Jaafar, 2003). It has been revealed that education has significant effect on mobile commerce adoption (Cullen \& Kabanda, 2018). This makes education and experience important factors to consider in the present study. The hypotheses tested are:

\section{$H_{1}$ : Education has significant effect on attitude to adopt and use of mobile commerce and service}

\section{H2: Experience has significant effect on attitude to adopt and use of mobile commerce and service}

According to Saffu, Walker and Hinson (2008), top management's enthusiasm to adopt information technology is one of the factors that contributes toward adoption of mobile commerce and service. Mirchandani and Motwani (2001) argued that the support from top management is essential and it serves as the factor that clearly differentiates between the adopters and non-adopters of mobile commerce and service. If the managers of an organization understand the role of mobile commerce and service, then they are more likely tend to influence organizational members to also embrace it. In addition to this, management will also commit resources for its adoption (Premkumar \& Roberts, 1999). There seems to be a lack of skills among small enterprises owners. This might affect the implementation of mobile commerce and service as a hindrance (Hussin et al., 2002). This attitude of management can have a positive management effect towards the use of mobile commerce and service activities. Thus, the following hypotheses are tested in the case of small enterprise owners in Ghana.

\section{$H_{3}$ : Attitude has significant effect on small enterprise owners' mobile commerce adoption}

\section{$H_{4}$ : Attitude has significant effect on small enterprise owners' mobile service adoption}

Environmental context tells about both the external and internal factors which influence SMEs adoption of mobile commerce and service. In this case, a company may feel pressured to adopt a new technology if business partners request or recommend the company to do so to facilitate business transactions. Dholakia and Kshetri (2004) argued that SMEs in developing countries are adopting mobile commerce and service due to the external pressure they receive from suppliers, customers and related business partners.

Related to experience of technology use are age and income levels of people. Is it expected that, as people age, they get into positions that make them mature to use internet and other IT related facilities. Chong (2013) revealed that age and education have significant relationships with the use of mobile commerce activities in China and South Africa (Cullen \& Kabanda, 2018). In the same vain, males report more intention to adopt mobile commerce than females (Dai, Singh \& Iyer, 2007) while males perceive more benefits than females in respect of using mobile commerce (Alduaij \& Al-Amari, 2016). Dai, Singh and Iyer (2007) reveal that older people are more likely to use mobile commerce to meet their entertainment needs and also search for information. Thus, hypotheses deducible are:

\section{$H_{5}$ : Males are more likely to adopt the use of mobile commerce and service than females}

$H_{6}$ : Age has significant effect on small enterprise owners' mobile commerce and service adoption

Income level is an important predictor of internet purchasing as earlier revealed by Sultan and Henrichs (2000). For Richa (2012), the results of income level does not significantly affect on-line shopping in India. On the other hand, earlier studies conducted by Sultan and Henrichs (2000) show that the consumer's willingness to and preference for adopting the internet based technology for shopping was positively related to the income level of respondents. Thus, it can be hypothesized that

\section{$H_{7}$ : Income level has significant effect on adoption of mobile commerce and service by small enterprise owners}

Relationships among players within the same industry also affect the overall industry structure (Gregor \& Johnston, 2000). These determine how competition among industry players and rivalry within the industry play a role in mobile commerce and service adoption. A company may feel pressure when it sees more and more companies in the industry adopting mobile commerce/service and therefore feels the need to adopt it as well, in order to remain competitive (Kuan \& Chau, 2001). There are various results in literature on how mobile commerce and service are affected. For instance, Chong, Ooi, Lin and Tang (2009) were of the view that decision to adopt mobile commerce technologies is influenced by the competitive pressure and market trends, Al-Zougool and Kurnia (2008) claimed market power leaders who adopt mobile service can force weaker or follower firms to also adopt such technologies to conform to industry standard. Similarly, if the industry is composed by duopolies or oligopolies, then any new initiative undertaken by one player has the tendency to be matched by the rest of the players due to their interdependencies. However, only few studies have explored how this factor affects the adoption of mobile commerce and service (Wymer \& Regan, 2005; Zhu, Kraemer \& Xu, 2003). 


\section{Methodology and Data}

\subsection{Design and Sampling}

The exploratory research design is used for the study to determine the factors influencing SMEs adoption of mobile commerce and service. This helps to describe variables, examine relationships and to determine the causes and effects relations among variables. Cross-sectional survey is used to collect primary data. The population comprised of SEs in Adentan Municipality with a sample size of 400 within the specified area. The sampling technique adopted for this study was convenient sampling technique.

A survey questionnaire with close-ended questions was used to collect data. The questionnaire on attitude and other variables were in Likert scale ranging from 1-5 indicating the degree of opinions. The questionnaires involved sections about the demographic characteristics of the respondents such as age, gender, educational level and marital status. Other sections covered income level, experiences, attitude of respondents, and actual use of mobile commerce and service.

\subsection{Model Specification and Analytical Techniques}

The study used structural equation modeling to ascertain how attitude is determined and its subsequent effect on mobile commerce and service. Theoretical literature (Ajzen, 1991; Fishbein \& Ajzen, 1975) and empirical literature (Al-Qirim, 2007; Kaynak, Tatoglu \& Kula, 2005; Mirchandani \& Motwani, 2001; Saffu, Walker \& Hinson, 2008) have opined that certain factors (Tuffour, Banor \& Akuffo, 2015) influence attitude to adopt the use of mobile facilities in business activities. Within this framework, the regression model is specified as:

ATT $=\beta_{0}+\beta_{1} G_{t}+\beta_{2}$ Age $_{t}+\beta_{3}$ Edu $_{t}+\beta_{4}$ Inc $_{t}+\beta_{5} \operatorname{Exp}_{\mathrm{t}}+\varepsilon_{\mathrm{t}}$

where,

ATT $=$ attitude

$\mathrm{G}=$ Gender

Age $=$ Age

Edu $=$ Education

Inc $=$ Monthly income

Exp $=$ Experience

$\varepsilon_{\mathrm{t}}=$ random error term

$\beta_{1}, \beta_{2}, \beta_{3} \beta_{4}$ and $\beta_{5}$ are the coefficients of regression, it is expected that $\beta_{1}>0 ; \beta_{2}>0 ; \beta_{3}>0, \beta 4>0$ and $\beta_{5}>0$. Specifically, regression analysis is used to ascertain the effect of the demographic and other factors on attitude to use mobile commerce and service. Gender is represented as dummy where males are represented as 1 and females otherwise. Age shows the number of years while education is rank ordered according to the education structure in Ghana. The more the number of years, the higher the educational level. It is expected that, as business income improves, attitude to adopt mobile facilities for business transactions would improve. Experience relates to prior use of related mobile and internet based facility. As such, experience is likely to enhance attitude to use mobile commerce and service.

\section{Results}

\subsection{Demographic Profile of Respondents}

In general, the setup of SEs mostly consists of more females than males owners. Regarding the gender distribution of the $400 \mathrm{SEs}$, more than half, $57.50 \%$ (230) of the respondents were females while the remaining $42.50 \%$ (170) represent males. From the results, it is evidence that the respondents are in different age categories. Those in 24-29 age bracket recorded a maximum of $21.8 \%$, and $7.8 \%$ for each of 54-59 and 60+. Relatively, younger people are in the informal sector since about $92.2 \%$ of respondents are less than 41 years.

The educational response of the study produced mixed results. About $22.75 \%$ (91) of respondents have obtained secondary school level certificate and $16.75 \%$ (67) of them have obtained undergraduate degree. The rest have had Higher National Diploma, Advanced Level, Diploma, no education, Ordinary Level, and masters with a recorded percentage of less than $13 \%$. As expected most SE operators do not really have higher qualification.

The number of respondents from the retail sector in the survey was $40.80 \%$. This is followed by the service providers, wholesalers and the manufacturers. They recorded $22.30 \%, 20.80 \%$ and $16.30 \%$ respectively. Most of the respondents fell within the married group with a record of $50.25 \%$. This is followed by the singles, recording about $32.75 \%$. In terms of marital status, the rest were divorced, widowers and widows. Generally, about $82.3 \%$ 
of the businesses owners earn not more than GHC1,000 monthly income.

\subsection{Structural Equation Model Results and Discussions}

The proposed variables in the model were tested using the structural equation modeling. The results of the path coefficients are presented in Figure 1

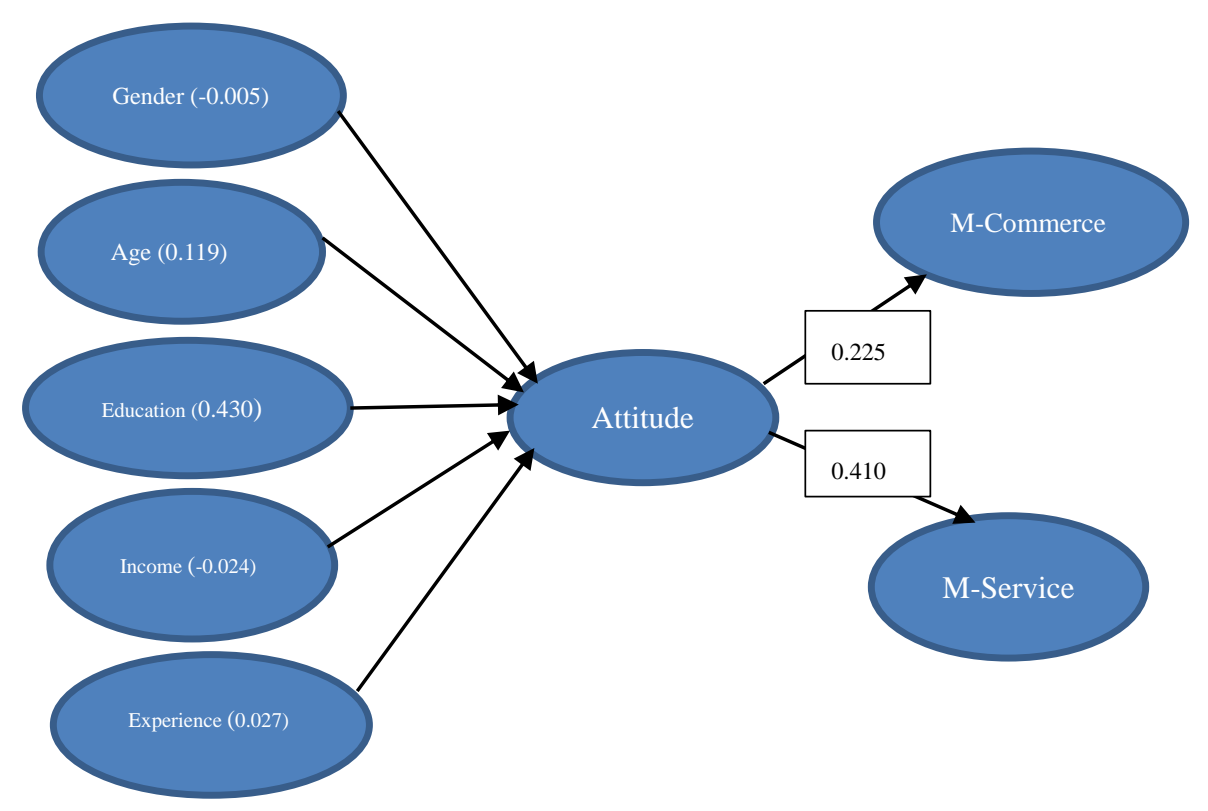

Figure 1. Path Coefficients of the Adoption of Mobile Commerce and Service

Figure 1 shows the coefficients of the adoption of mobile commerce and service. The path coefficients represent standardized versions of the linear regression weights. These are used to examine the causal linkage between independent and dependent variables. Gender (with male dummy value of 1) has a negative influence (value of -0.005 ) on the attitude of the usage of mobile commerce and service. This implies females are more likely to have the attitude to use mobile commerce and service than men, though this has very small coefficient. This results contradicts those indicated by Dai, Singh and Iyer (2007) and, Alduaij and Al-Amari (2016) where males are more likely to use mobile service than females.

Also there is a positive effect of age on attitude, with indicative coefficient of 0.119 showing that the higher the age, the more positive attitude they have towards the use of mobile commerce and service. This also supports literature such as Dai, Singh and Iyer (2007) and Chong (2013). Education also has a positive effect on attitude towards the use of mobile commerce and service. From Figure 1, the higher the educational level of business owners, the higher the attitude of respondents' use of mobile commerce and service, this is shown by a coefficient of 0.430 . The results of Chong (2013) and, Cullen and Kabanda (2018) are in line with the present study while Roberts and Toleman (2007) indicate that knowledge is most influential only at the earlier stage of adoption.

Experience which entailed ICT facilities usage, expectation from the use of mobile commerce and service, and social media integration has a positive effect on attitude towards mobile commerce and service usage. This results support the conclusions of Dai, Singh and Iyer (2007). For Khalifa and Cheng (2002), different years of experience of people in using mobile devices have different effects on the individual user's adoption of mobile commerce. Interestingly, income has negative influence on SEs attitude on usage of mobile commerce and service. The income level of an individual does not determine the attitude to use mobile commerce and service. Richa (2012) and, Sultan and Henrichs (2000) results report the opposite, where income is important determinant of adopting internet based transactions.

The implication is that, the higher the income level, the less the attitude to use more mobile commerce and serves. Thus, as people become richer, they tend to use other financial transaction modes such as cheques and bank transfers. Attitude has positive effect on both mobile commerce and service. The coefficient for mobile service is higher than mobile commerce. Thus, SEs have more attitude to use mobile service than mobile commerce, although, attitude has positive effect on both mobile commerce and serves. 


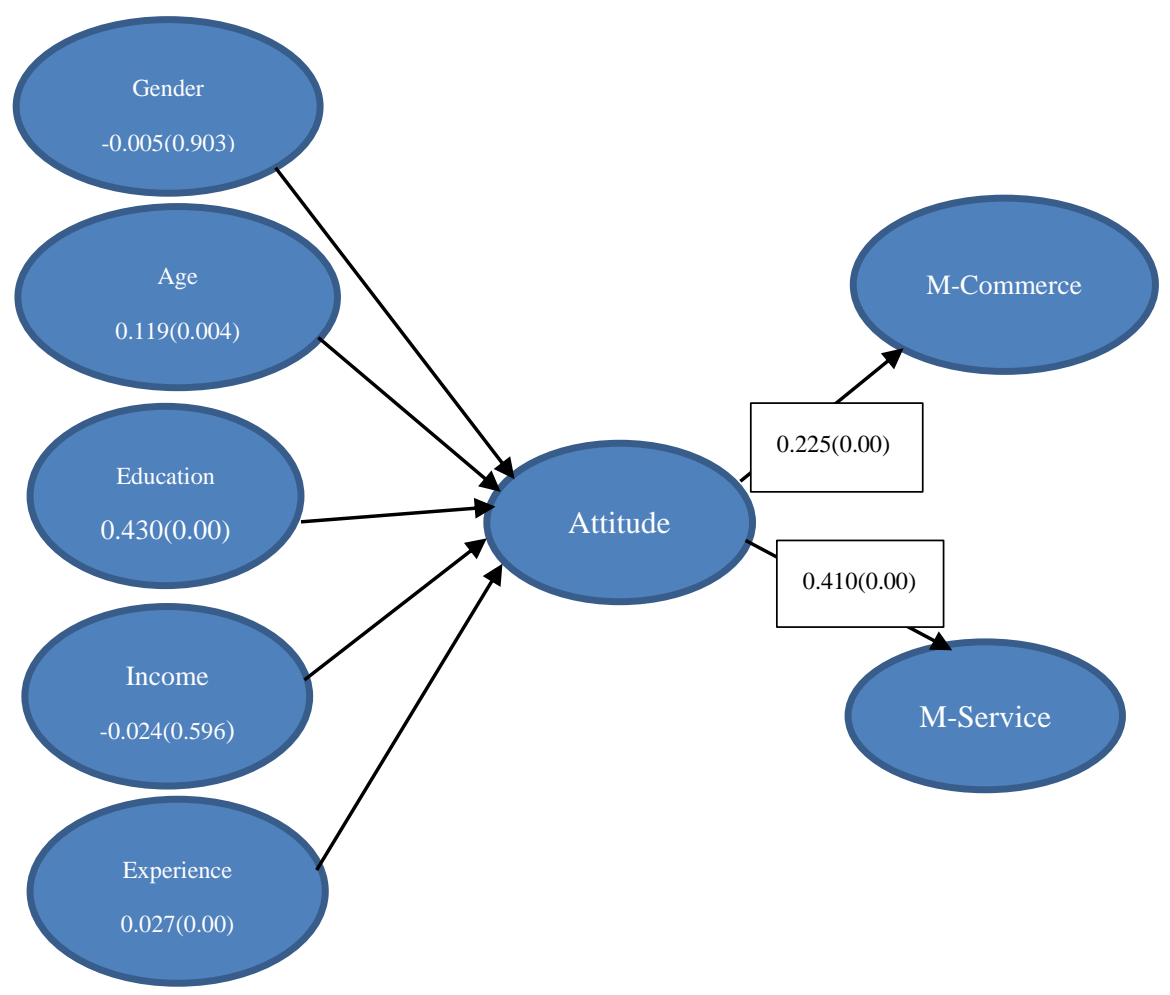

Figure 2. Significance of the Variables

Source: Survey Data, 2018

Figure 2 represents the Bootstrapping results which show the significance of the variables. Among the demographic characteristics, gender, age, education, income and experience have been specially addressed in this study. From Figure 2, being males and income level have no significance towards the attitude to use mobile commerce and service. Gender and income indicated p-value of greater than 0.05 (that is 0.903 and 0.596 respectively).

Education has the strongest significance in one's attitude towards the use of mobile commerce and service, the higher the educational level, the higher the level of one's attitude towards the use of mobile commerce and service. Experience is one of the key elements influencing the level of usage of information technology as indicated by Jaeger (2003). Kalliny and Minor (2006) also indicated that, the higher the level of education of an adult is, the more likely such an adult will use computers and the internet. Education has significant effect on attitude.

Attitude of individuals and actual usage of mobile commerce and service are factors used in some previous studies. From the analysis, there is empirical support regarding the causal link between use intention and actual use in the adoption of mobile facilities. From Figure 2, there is significant effect of attitude in the adoption of mobile commerce and service usage among small enterprises in Adenta municipality. The attitude of respondents of SEs influences its usage of mobile commerce and service.

\section{Conclusion}

The study concludes that educational level was observed to have the best positive influence on the attitude towards adoption of mobile commerce and mobile service. In addition, experience of respondents was also found to have positive influence on the attitude of individuals for actual use of mobile commerce and mobile service. In other words, experienced people use these technologies more. Surprisingly, being males and income level do not show any significant influence on attitude to adopt mobile commerce and service. Also, small enterprise owners' attitude is a significant determinant for the use of mobile commerce and service.

Our results provide a significant insight for policy makers regarding how to promote mobile commerce and service in Ghana. However, the use of larger samples, which may lead to more intuition into the use of mobile technologies among SMEs may be helpful. Second, an extension of the study to consider the influence of nature of business and other work climate on mobile technologies from different sectors may also be insightful. 


\section{References}

Ajzen, I. (1991). The theory of planned behavior. Journal of Organizational Behavior and Human Decision, 50(2), 179-211. https://doi.org/10.1016/0749-5978(91)90020-T

Alduaij, M., \& Al-Amari, H. (2016). Factors moderating students adoption decisions of mobile commerce. Review of Public Administration Management, 4(1), 1-7. https://doi.org/10.4172/2315-7844.1000180

Alexander, C. A. (2006). Study of the environmental, organizational, and information technology issues in e-business adoption and assimilation in small firms. Southern Illinois University, Carbondale, Illinois.

Allil, K., \& Khan, M. N. (2016). Factors affecting adoption of mobile services. International Review of Management and Marketing, 6(S4) 125-131.

Al-Qirim, N. (2007). The adoption of commerce communications and applications technologies in small businesses in New Zealand. Electronic Commerce Research and Application, 6(4), 462-473. https://doi.org/10.1016/j.elerap.2007.02.012

Al-Zougool, B., \& Kurnia, S. (2008). Electronic commerce technologies adoption by SMEs: A comceptual study. ACIS 2008 Proceedings, Paper 72. Retrieved January 23, 2018, from http://people.eng.unimelb.edu.au/sherahk/Papers/ACIS-SMEs.pdf

Bank of Ghana. (2017). Impact of mobile money on the payment system in Ghana: An econometric analysis, Payment Systems Department, Accra.

Barua, A., Whinston, A., \& Yin, F. (2000a). Value and productivity in the internet economy. Computer, 33(5), 102-105. https://doi.org/10.1109/2.841787

Barua, A., Whinston, A., \& Yin, F. (2000b). Assesing internet enabled business value: An exploratory investigation. Working Paper, Center of Research in Electronic Commerce, the University of Texas at Austin, Austin.

Bouwman, H., Carlsson, C., Molina-Castillo, F. J., \& Walden, P. (2007). Barriers and drivers in the adoption of current and future mobile services in Finland. Telematics and Informatics, 24, 145-160. https://doi.org/10.1016/j.tele.2006.08.001

Chong, A. (2013). Mobile commerce usage activities: The roles of demographic and motivation variables, Technological Forecasting and Social Change, 80(7), 1350-1359. https://doi.org/10.1016/j.techfore.2012.12.011

Chong, A. Y. L., Ooi, K. B., Lin, B., \& Tang, S. Y. (2009). Influence of interorganizational relationships on SMEs' e-business adoption. Internet Research, 19(3), 313-331. https://doi.org/10.1108/10662240910965379

Cullen, M., \& Kabanda, S. K. (2018). The role of demographic and motivational factors on mobile commerce usage activities in South Africa. South African Journal of Information Management, 20(1), a817. https://doi.org/10.4102/sajim.v20i1.817

Dai, H., Singh, R., \& Iyer, L. (2007). Intention to use mobile commerce: A demographic analysis of the Chinese market, AMCIS 2007 Proceedings. 263. http://aisel.aisnet.org/amcis2007/263

Daniel, E. \& Wilson, H. (2002). Adoption intention and benefits realized: A study of e-commerce in UK SMEs. Journal of Small Business and Enterprise Development, 9(4), 331-348. https://doi.org/10.1108/14626000210450522

Davis, F., Bagozzi, R., \& Warshaw, P. (1989). User acceptance of computer technology: Acomparison of two theoritical models. Management Science, 35(8), 982-1005. https://doi.org/10.1287/mnsc.35.8.982

Dholakia, R. R., \& Kshetri, N. (2004). Factors impacting the adoption of the internet among SMEs. Small Business Economics, 23(4), 311-322. https://doi.org/10.1023/B:SBEJ.0000032036.90353.1f

Dillion, A., \& Morris. (1996). User acceptance of new information technology: Theories and models. In M. Williams (ed.) Annual Review of Information Science and Technology, 31, Medford NJ: Information Today, 3-32.

Fishbein, M., \& Ajzen, I. (1975). Belief, attitude, intention and behavior: An introduction to theory and research. Reading, MA: Addison-Wesley.

Gibbs, J. L., \& Kraemer, K. L. (2004). A cross-country investigation of the determinants of scope of e-commerce use: An institutional approach. Electronic Markets, 14(2), 124-137. https://doi.org/10.1080/10196780410001675077

Grandon, E., \& Pearson, J. M. (2004). Electronic commerce adoption: An empirical study of small and medium US businesses. Information \& Management, 42(1), 197-216. https://doi.org/10.1016/j.im.2003.12.010

Gregor, S., \& Johnston, R. B. (2000). Developing an understanding of inter-organizational systems: Argument 
for multi-level analysis and structuration theory. Proceedings of the 8th European Conference on Information Systems. Vienna, Austria.

Hennessy, M. (2012). Advancing reasoned action theory. The Annals of the America Academy of Political Social Science, Vol. 640, Sage Publications. https://doi.org/10.1177/0002716211424709

Hong, W., \& Zhu, K. (2006). Migrating to internet-based e-commerce: Factors affecting e-commerce adoption and migration at the firm level. Information \& Management, 43(2), 204-221. https://doi.org/10.1016/j.im.2005.06.003

Hovav, A., Patnayakuni, R., \& Schuff, D. (2004). A model of internet standards adoption: The case of IPv6. Information Systems Journals, 14(3), 265-294. https://doi.org/10.1111/j.1365-2575.2004.00170.x

Hussin, H., King, M., \& Cragg, P. B. (2002). IT alignment in small firms. European Journal of Information Systems, $11(2), 108-127$. https://doi.org/10.1057/palgrave/ejis/3000422

Huy, L. V., \& Filiatrault, P. (2006). The adoption of e-commerce in SMEs in Vietnam: A study of users and prospectors. Proceedings of the 10th Pacific Asia conference on information systems, Kuala Lumpur, Malaysia, 1335-1345.

Jaegar, P. T. (2003). The endless wire: E-government as global phenomenon. Government Information Quarterly, 20(4), 323-331. https://doi.org/10.1016/j.giq.2003.08.003

Jeon, B. N., Han, K. S., \& Lee, M. J. (2006). Determining factors for the adoption of e-business: The case of SMEs in Korea. Applied Economics, 38(16), 1905-1916. https://doi.org/10.1080/00036840500427262

Johnston, D. A., Wade, M., \& McClean, R. (2007). Does e-business matter to SMEs? A comparison of the financial of internet business solutions on European and North American SMEs. Journal of Small Business Management, 45(2), 354-361. https://doi.org/10.1111/j.1540-627X.2007.00217.x

Kalliny, M., \& Minor, M. (2006). The antecedents of m-commerce adoption. Journal of Strategic E-Commerce, $4(2), 81-99$.

Kaynak, E., Tatoglu, E., \& Kula, V. (2005). An analysis of the factors affecting the adoption ofelectronic commerce by SMEs: Evidence from an emerging market. International Marketing Review, 22(6), 623-640. https://doi.org/10.1108/02651330510630258

Keeling, K., Vassilopoulou, K., McGoldrick, P., \& Macaulay, L. (2000). Market realities and innovation in small to medium enterprises: Facilitators and barriers to the use of electronic commerce. New Product Development and Innovation Management, 2(1), 57-70.

Khalifa, M., \& Cheng, S. K. N. (2002). Adoption of mobile commerce: Role of exposure, Proceedings of the 35th Hawaii International Conference on System Sciences, Hawaii.

Kim, C., Mirusmonov, M., \& Lee, I. (2010). An empirical examination of factors influencing the intention to use mobile payments. Computers in Human Behavior, 26(3), 310-322. https://doi.org/10.1016/j.chb.2009.10.013

Kuan, K., \& Chau, P. (2001). A perception-based model for EDI adoption in small businesses using technology-organization-environment framework. Information and Management, 38(8), 507-521. https://doi.org/10.1016/S0378-7206(01)00073-8

Laudon, K. C., \& Traver, C. G. (2003). E-commerce business, technology, society (International ed.). Boston, MA: Addison Wesley.

Lee, H. H., \& Lee, S. E. (2007). Mobile commerce: An analysis of key success factors. Journal of Shopping Center Research, 14(2), 29-62.

Mallat, N., Rossi, M., Tuunainen, V. K., \& Oorni, A. (2009). The impact of used context on mobile services acceptance: The case of mobile ticketing. Iinformation and Management, 46, 190-195. https://doi.org/10.1016/j.im.2008.11.008.

Mirchandani, A., \& Motwani, J. (2001). Understanding small business electronic adoption: An empirical analysis. Journal of Computer Information Systems, 41(3), 70-73.

Ngai, E. W. T., \& Gunasekaran, A. (2007). A review for mobile commerce research and application. Decision Supports Systems, 43(1), 3-15. https://doi.org/10.1016/j.dss.2005.05.003

Poon, S., \& Swatman, P. M. C. (1999). A longitudinal study of expectations in small business internet commerce. International Journal of Electronic Commerce, 3(3), 21-33. https://doi.org/10.1080/10864415.1999.11518339

Premkumar, G., \& Roberts, M. (1999). Adoption of new information technologies in rural small businesses.Omega: The international Journal of Management Science, 27(4), 467-484. https://doi.org/10.1016/S0305-0483(98)00071-1 
Qureshi, S., Keen, P., \& Kamal, M. (2010). Business models faor development: The global capability sourcing model. In S. Kamel (Eds.), E-strategies for technological diffusion and adoption: National ICT approaches for socioeconomic development (pp. 200-214). Hershey, PA: IGI Global. https://doi.org/10.4018/978-1-60566-388-3.ch011

Raymond, L., Bergeron, F., \& Blili, S. (2005). The assimiliation of e-business in manufacturing SMEs: Determinants and effects on growth and internationalization. Electronic Markets, 15(2), 106-118. https://doi.org/10.1080/10196780500083761

Richa, D. (2012). Impact Of demographic factors of consumers on online shopping behaviour: A Study of consumers in India, International Journal of Engineering and Management Sciences, 3(1), 43-52.

Roberts, B., \& Toleman, M. (2007). One-size e-business adoption model does not fit all. Journal of Theoritical and Applied Electronic Commerce Research, 2(3), 49-61.

Rogers, E. M. (1995). Diffusion of innovations, ( $4^{\text {th }}$ ed.). New York: The Free Press.

Rouse, M. (2005). Investopedia business. Retrieved from Investopedia: http://searchmobilecomputing.techtarget.com/definition/m-commerce.

Saffu, K., Walker, J. H., \& Hinson, R. (2008). Strategic value and electronic adoption among small and medium-sized enterprises in a transitional economy. Journal of Business \& Industrial Marketing, 23(6), 395-404. https://doi.org/10.1108/08858620810894445

Sahin, I. (2006). Detailed review of Rogers' Diffusion of Innovation Theory and educational technology- related studies based on Rogers' Theory. The Turkish Online Journal of Educational Technology, 5(2), article 3.

Shih, H. (2008). Contagion effects of electronic commerce diffusion: Perspective from network analysis of industrial structure. Technological Forecasting \& Social Change, 75(1), 78-90. https://doi.org/10.1016/j.techfore.2006.10.002

Spectrum. (1997). Moving into the information society. London: HMSO.

Sulaiman, A., \& Jaafar, N. (2003, October 7). An overview of e-commerce practices among small retailers in four cities. Proceedings of the national seminar on electronic commerce, Universiti Tun Abdul Razak, Petaling Jaya, Malaysia.

Sultan, F., \& Henrichs, R. B. (2000). Consumer preferences for Internet services over time: Initial explorations. The Journal of Consumer Marketing, 17(5), 386-403. https://doi.org/10.1108/07363760010341036

Teo, T. S., \& Ranganathan, C. (2004). Adopters and non-adopters of business-to-business electronic commerce in Singapore. Information and Management, 42(1), 89-102. https://doi.org/10.1016/j.im.2003.12.005

Tuffour, J. K., Banor, C., \& Akuffo, E. (2015). Do leadership styles matter in microfinance performance? Empirical evidence from Ghana, Journal of Business Research, (9), 1-15.

Tuffour, J. K., \& Owusu, P. A. (2018). Profitability of listed Ghanaian banks determined by the stylized facts, International Journal of Applied Economics and Finance, 12(1), 1-8. https://doi.org/10.3923/ijaef.2018.1.8.

Tuffour, J. K., \& Mensah, T. (2018). The effects of governance type and economic crises on foreign direct investment inflows in Ghana: Evidence from 1960-2015, Review of Foreign Trade, 53(2), 63-80. https://doi.org/10.1177/0015732517734026

Turban, E., King, D., Lee, J., Liang, T. P., \& Turban, D. (2010). Electronic commerce: A managerial perspective 2010. Upper Saddle River, NJ: Pearson Prentice Hall.

Wymer, S., \& Regan, E. (2005). Factors influencing e-commerce adoption and use by small and medium businesses. Electronic Markets, 15(4), 438-453. https://doi.org/10.1080/10196780500303151

Zhou, T. (2011). An empirical examination of users' post-adoption behaviour of mobile services. Behaviour and Information Technology, 30(2), 241-250. https://doi.org/10.1080/0144929X.2010.543702

Zhu, K., Kraemer, K., \& Xu, S.(2003). Electronic business adoption by European firms: A cross-country assessment of the facilitators and inhibitors. European Journal of Information Systems, 12(4), 251-268. https://doi.org/10.1057/palgrave.ejis.3000475

\section{Copyrights}

Copyright for this article is retained by the author(s), with first publication rights granted to the journal.

This is an open-access article distributed under the terms and conditions of the Creative Commons Attribution license (http://creativecommons.org/licenses/by/4.0/). 